\title{
Hydroxyapatite bioactivated bacterial cellulose promotes osteoblast growth and the formation of bone nodules
}

\author{
Neftaha Tazi ${ }^{1,3}$, Ze Zhang ${ }^{2}$, Younès Messaddeq ${ }^{3}$, Luciana Almeida-Lopes ${ }^{4}$, Lisinéia M Zanardi ${ }^{4}$, \\ Dennis Levinson ${ }^{5}$ and Mahmoud Rouabhia ${ }^{1 *}$
}

\begin{abstract}
The goal of this study was to investigate the feasibility of bacterial cellulose (BC) scaffold to support osteoblast growth and bone formation. BC was produced by culturing Acetobacter xylinum supplemented with hydroxyapatite (HA) to form BC membranes (without HA) and BC/HA membranes. Membranes were subjected to X-ray photoelectron spectroscopy (XPS) analysis to determine surface element composition. The membranes were further used to evaluate osteoblast growth, alkaline phosphatase activity and bone nodule formation. BC was free of calcium and phosphate. However, XPS analysis revealed the presence of both calcium (10\%) and phosphate (10\%) at the surface of the $\mathrm{BC} / \mathrm{HA}$ membrane. Osteoblast culture showed that $\mathrm{BC}$ alone was non-toxic and could sustain osteoblast adhesion. Furthermore, osteoblast adhesion and growth were significantly $(p \leq 0.05)$ increased on BC/HA membranes as compared to $B C$ alone. Both $B C$ and $B C / H A$ membranes improved osteoconductivity, as confirmed by the level of alkaline phosphatase (ALP) activity that increased from $2.5 \mathrm{mM}$ with BC alone to $5.3 \mathrm{mM}$ with $\mathrm{BC} / \mathrm{HA}$. BC/HA membranes also showed greater nodule formation and mineralization than the BC membrane alone. This was confirmed by Alizarin red staining (ARS) and energy dispersive X-ray spectroscopy (EDX). This work demonstrates that both $\mathrm{BC}$ and $\mathrm{BC} / \mathrm{HA}$ may be useful in bone tissue engineering.
\end{abstract}

Keywords: Acetobacter xylinum, Hydroxyapatite, Osteoblasts, Tissue regeneration, Cellulose

\section{Introduction}

Developing effective bone regeneration therapy is a clinically important long-term goal. Bone loss caused by trauma, neoplasia, reconstructive surgery, congenital defects, or periodontal disease is a major health problem worldwide. Indeed, close to 6 million fractures occur annually in the United States. Of these, 5 to $10 \%$ (0.3 to 0.6 million) fail to heal properly due to non-union or delayed union (Franceschi 2005; Bostrom et al., 1999). In the case of periodontal disease, nearly half of adults between the ages of 45 and 65 have moderate to advanced periodontitis and associated alveolar bone loss, which, if not reversed, will result in the loss of almost 6.5 teeth/individual (Oliver et al. 1998). Clearly, there is a need for

\footnotetext{
* Correspondence: mahmoud.rouabhia@fmd.ulaval.ca

'Groupe de Recherche en Écologie Buccale, Faculté de Médecine Dentaire, Université Laval, 2420, rue de la Terrasse, Québec, QC G1V OA6 Québec, Canada

Full list of author information is available at the end of the article
}

safe, effective methods to replace and promote bone regeneration. Advances in bone regeneration therapy will require innovative molecular biology and tissue engineeringbased technologies. The regeneration of complex bone structures such as joints, craniofacial structures, or even entire bones and teeth will involve vastly more complex challenges including appropriate scaffold.

Scaffold is crucial in tissue engineering as a delivery vehicle for cell transplantation, a three-dimensional template for tissue regeneration, and as a matrix for signal transduction to regulate bone formation (Harris et al., 1998). Scaffold also serves as a reservoir for different molecules such as water and nutrients, and for various cell mediators such as cytokines and growth factors. Recent literature underscores the key role of the scaffold in influencing cell and tissue function (O'Brien et al., 2007; Bitar et al., 2008). Scaffold must be biocompatible to overcome adverse inflammatory responses and preferably be biodegradable to yield

\section{空}


space for new tissue formation (Holland and Mikos 2006). The physical (porosity, topography) and chemical (material composition) properties of scaffold material should also suit a specific application. For example, to mimic native bone a scaffold must be osteoconductive and preferably, osteoinductive (Hasegawa et al., 2007). Type I collagen, hydroxyapatite and other calcium phosphate biomaterials are commonly used in bone tissue engineering (Wahl et al., 2007). These materials promote osteoblast and osteoprogenitor attachment, and differentiation to enhance bone formation (Wahl et al., 2007; Wang et al., 2007; Huang et al., 2007). Naturally derived materials such as collagen have limitations such as weak mechanical properties, while undesirable degradation profiles hamper the utility of hydroxyapatite. To overcome these limitations naturally derived materials can be combined with synthetic materials offering improved mechanical properties. Indeed, synthetic biodegradable polymers such as polyglycolide (PGA), polylactide (PLA), poly(E-caprolactone) (PCL) and their copolymers have been widely used to fabricate clinically useful scaffolds (Gong et al., 2007; Buxton and Cobourne 2007). These were further improved by introducing natural proteins such as collagen, gelatin and growth factors (Garg et al., 2012). Many of the mechanical properties of these synthetic polymers are found in bacterial cellulose.

Bacterial cellulose (BC) produced from Acetobacter xylinum is a biocompatible polymer with excellent physical and chemical properties characterized by high tensile strength, elastic modulus and hydrophilicity (Helenius et al., 2006). Morphologically, the fibrous structure of $\mathrm{BC}$ is similar to the collagenous fibers of bone. These characteristics support BC as a useful scaffolding material in regenerative medicine (Bäckdahl et al., 2006; Andrade et al., 2010; Hong et al., 2006). Fang et al. 2009 recently reported a HA/BC nanocomposite scaffold supporting the growth and differentiation of human bone marrow stromal cells (MSCs). Also, recent studies have focused on the fabrication and characterisation of $\mathrm{HA} / \mathrm{BC}$ as a composite material using a different method of appetite incorporation (Grande et al., 2009; Bodin et al., 2006) although, without consideration of the interaction of these composite materials with cell viability and function. However, study of $\mathrm{BC}$ as a bone regeneration scaffold is preliminary and the data are limited. The purpose of this study was to investigate whether BC and BC-hydroxyapatite (HA) can promote osteoblast growth and bone nodule formation.

\section{Materials and methods} Production of BC membrane

Acetobacter xylinum (ATCC 52582) obtained from the American Type Culture Collection (Rockville, MD) was cultivated in $20 \mathrm{~mL}$ of medium in $100 \mathrm{~mL}$ flasks for
$120 \mathrm{~h}$ at $28^{\circ} \mathrm{C}$ in static culture. The nutrient medium contained 2 wt $\%$ glucose, 0.5 wt $\%$ peptone, 0.5 wt $\%$ yeast extract, $0.27 \mathrm{wt} \%$ disodium hydrogen phosphate and $0.115 \mathrm{wt} \%$ citric acid. Bacterial cellulose pellicles were harvested and cleaned by immersion in $2 \mathrm{wt} \%$ $\mathrm{NaOH}$ solution at $80^{\circ} \mathrm{C}$ for $1 \mathrm{~h}$. The pellicles were then immersed in $1 \mathrm{wt} \% \mathrm{NaClO}$ solution for $30 \mathrm{~min}$, washed with deionized water and sterilized by autoclaving $\left(121^{\circ} \mathrm{C}\right.$ for $\left.15 \mathrm{~min}\right)$.

\section{Production of BC supplemented with HA (BC/HA)}

Two methods were used to introduce HA into BC.

Surface deposition of HA onto BC. HA was formed in $\mathrm{BC}$ hydrogel by performing alternating incubation cycles with calcium and phosphate solutions (Hutchens et al., 2006). Briefly, BC membranes were incubated in a solution of $\mathrm{CaCl}_{2}(11 \mathrm{~g} / \mathrm{L})$ at $\mathrm{pH} 4.83$ under agitation in an orbital shaker for $12 \mathrm{~h}$ at $23^{\circ} \mathrm{C}$. The membranes were rinsed with deionized water and then incubated in a $\mathrm{Na}_{2} \mathrm{HPO}_{4}$ solution $(8.52 \mathrm{~g} / \mathrm{L})$ for $12 \mathrm{~h}$. The samples were then rinsed in deionized water and dried at $60^{\circ} \mathrm{C}$ to constant weight. The mass of HA in the cellulose was determined by subtracting the total composite weight from the average weight of control cellulose membranes. HA weight percentages were calculated by dividing the mass of the HA by the total composite weight. This was estimated at $50 \%$ of $\mathrm{HA}$ in the $\mathrm{BC} /$ HA membrane.

Hydroxyapatite mixture with the bacterial cellulose pulp. BC hydrogel was mechanically cut into slices to generate a BC pulp of $10 \%$ cellulose. After homogenization, $\mathrm{BC}$ solution was supplemented with hydroxyapatite at a $0.33 \%$ as previously reported (Varma and Babu 2005). The mixture was then vigorously stirred, poured into rectangular molds and dried at room temperature before use.

\section{X-ray photoelectron spectroscopy (XPS) analysis}

The surface chemical elements of $\mathrm{BC}, \mathrm{BC} / \mathrm{HA}(50 \%)$ and $\mathrm{BC} / \mathrm{HA}(0.3 \%)$ membranes were analyzed with a PerkinElmer PHI 5600 XPS (Eden Prairie, MN) with a standard magnesium X-ray source $(1253.6 \mathrm{eV})$. The emitted photoelectrons were detected at a $45^{\circ}$ take-off angle and analyzed with a hemispheric electron energy analyzer operated at a pass energy of $187.9 \mathrm{eV}$ for the survey scans. For each membrane three locations of $0.8 \times 0.8 \mathrm{~mm}^{2}$ each were analyzed and averaged. The vacuum in each sample chamber was maintained at 10-10 torr during measurement. All measurements were done at the air-facing side of the membranes, which is the side that faced air during membrane preparation. 


\section{Osteoblast culture}

Saos2 osteoblast-like cells, a human osteosarcoma cell line with osteoblastic properties, were used in this study. The osteoblasts were cultured in a 3:1 mixture of Dulbecco-Vogt's modified Eagle's (DME) medium and Ham's F-12 (H) (Invitrogen Life Technologies, Burlington, ON, Canada) supplemented with $24.3 \mu \mathrm{g} / \mathrm{ml}$ adenine, $10 \mu \mathrm{g} / \mathrm{ml}$ human epidermal growth factor (Chiron Corp., Emeryville, CA, USA), $0.4 \mu \mathrm{g} / \mathrm{ml}$ hydrocortisone (Calbiochem, La Jolla, CA, USA), $5 \mu \mathrm{g} / \mathrm{ml}$ bovine insulin, $5 \mu \mathrm{g} / \mathrm{ml}$ human transferrin, $2 \times 10^{-9}$ M 3,3,5'-triiodo-Lthyronine, $100 \mathrm{U} / \mathrm{ml}$ penicillin, $25 \mu \mathrm{g} / \mathrm{ml}$ gentamicin (Schering, Pointe-Claire, QC, Canada), and 10\% foetal calf serum (NCS, fetal clone II; Hyclone, Logan, UT, USA). Sub-confluent cell cultures were trypsinized; cells were split 1:10 to maintain cell growth, and were subsequently incubated at $37^{\circ} \mathrm{C}$ in a humid $8 \% \mathrm{CO}_{2}$ atmosphere.

\section{Hoechst staining}

Osteoblasts were seeded onto the different BC membranes at $5 \times 10^{5}$ for two days. Adherent cells were subjected to Hoechst staining. The samples were first fixed with methanol/glacial acetic acid (75/25) for $3 \times 15 \mathrm{~min}$, and washed 3 times with PBS. They were then incubated with Hoechst 33342 (H42) (Riedel de Haen, Seele, Germany) $(1 \mu \mathrm{g} / \mathrm{ml})$ in PBS for $15 \mathrm{~min}$ at room temperature in a dark atmosphere. After three washes with deionized water, the samples were observed and photographed using an epifluorescence light microscope (Axiophot, Zeiss, Oberkochen, Germany).

\section{Lactate dehydrogenase assay}

Since LDH is a soluble cytosolic enzyme that is released into the culture medium following loss of membrane integrity resulting from either apoptosis or necrosis (Melo et al., 2007), it was used in our experiments to assess possible cytotoxicity resulting from $\mathrm{BC}$ membranes. Osteoblasts were seeded onto $\mathrm{BC}$ and $\mathrm{BC} / \mathrm{HA}$ membranes and then cultured for 2 days. At this time medium was refreshed and cells were cultured for an additional two and four days. Culture supernatant was collected at days two and four for LDH assessment; 4 and 6 day cultures respectively after seeding. LDH activity was measured using an LDH cytotoxicity assay (Promega, Madison, WI), per the manufacturer's protocol. Briefly, $50 \mu \mathrm{l}$ of each supernatant were transferred to a 96-well flat-bottom plate and supplemented with $50 \mu \mathrm{l}$ reconstituted substrate mix. The plate was incubated in the dark at room temperature for $30 \mathrm{~min}$. This assay is based on the conversion of L-lactate and NAD to pyruvate and NADH by released LDH (Gleitz et al., 1996). To stop the reaction a volume of $50 \mu \mathrm{l}$ of an acid solution was added to each well, after which approximately
$100 \mu \mathrm{l}$ of each reacted solution was transferred to a 96well flat-bottom plate, and absorbance read at $490 \mathrm{~nm}$ with a X-Mark Microplate Spectrophotometer (Bio-Rad, Mississauga, ON, Canada). A positive control for total LDH activity release was added to the experiment. Both positive (PC) and negative controls (NC) were included. $\mathrm{LDH}$ release was calculated using the following formula:

$$
\begin{aligned}
\text { Total LDH release }(\%)= & \left(\left(\mathrm{BC}_{\mathrm{absorbance}}-\mathrm{NC}_{\mathrm{absorbance}}\right)\right. \\
& \left.\div\left(\mathrm{PC}_{\mathrm{abssbance}}-\mathrm{NC}_{\mathrm{absorbance}}\right)\right) \\
& \times 100 \%
\end{aligned}
$$

\section{MTT assay of osteoblasts cultured on BC membranes}

Osteoblasts $\left(5 \times 10^{5}\right)$ were cultured on $\mathrm{BC} / \mathrm{HA}$ membranes for 2,4 and 6 days before being subjected to MTT [(3-(4,5-dimethylthiazol-2-yl)-2,5-diphenyltetrazolium-bromide)] assay as we previously reported (Denizot and Lang 1986). BC membranes that do not contain hydroxyapatite were used as control. A second control, i.e., $\mathrm{BC} / \mathrm{HA}$ and $\mathrm{BC}$ membranes that were not seeded with osteoblasts, was also included. This allows for the measurement of non-specific adsorption of MTT to the BC membranes. Osteoblasts on each membrane were cultured in the presence of $1 \%(\mathrm{v} / \mathrm{v})$ MTT solution $(5 \mathrm{mg} / \mathrm{mL})$ for $4 \mathrm{~h}$, after which the supernatant was removed and the cultures were washed with PBS. Then $1 \mathrm{~mL}$ of $\mathrm{HCl}$ in isopropanol $(0.04 N)$ was added and incubated for 15 min. At the end of the incubation, $200 \mu \mathrm{L}$ (in triplicate) of solution was transferred from each membrane to a 96-well flat-bottom plate, and the absorbance of the MTT (formazan) was determined at $550 \mathrm{~nm}$ using an ELISA reader (Model 680, BioRad Laboratories, Mississauga, ON, Canada).

\section{Alkaline phosphatase assay}

Alkaline phosphatase (ALP) activity in the supernatant of osteoblast cultured membranes was measured. In preparation for this assay, Saos2 cells $\left(5 \times 10^{5}\right)$ were seeded on $\mathrm{BC}, \mathrm{BC} / \mathrm{HA}(50 \%)$ and $\mathrm{BC} / \mathrm{HA}(0.3 \%)$ membranes and allowed to adhere overnight. Medium was refreshed and cells were cultured for 2 and 4 days at $37^{\circ} \mathrm{C}$ in a $5 \% \mathrm{Co}_{2}$ humid atmosphere. At the end of each culture period, medium was collected and centrifuged twice at $3000 \mathrm{rpm}$ for 10 min to eliminate cell debris and ALP enzyme activity was assayed. One hundred $\mu \mathrm{L}$ of collected culture medium was supplemented with $100 \mu \mathrm{L}$ of substrate solution (100 mg of 4-nitrophenyl phosphate disodium salt hexahydrate in $\left.25 \mathrm{~mL} \mathrm{H}_{2} \mathrm{O}\right)$ and $20 \mu \mathrm{L}$ of alkaline buffer solution $(1.5 \mathrm{M}$ 2-amino-2-2 methyl-1-propanolol at $\mathrm{pH}$ of 10.3) in a 96 well plate, and the plate was incubated for 1 hour at $37^{\circ} \mathrm{C}$. The reaction was stopped by adding $100 \mu \mathrm{L} 0.3 \mathrm{M}$ $\mathrm{NaOH}$ to each well. Optical density was read at $405 \mathrm{~nm}$ using an X-Mark microplate spectrophotometer (Bio-Rad, 


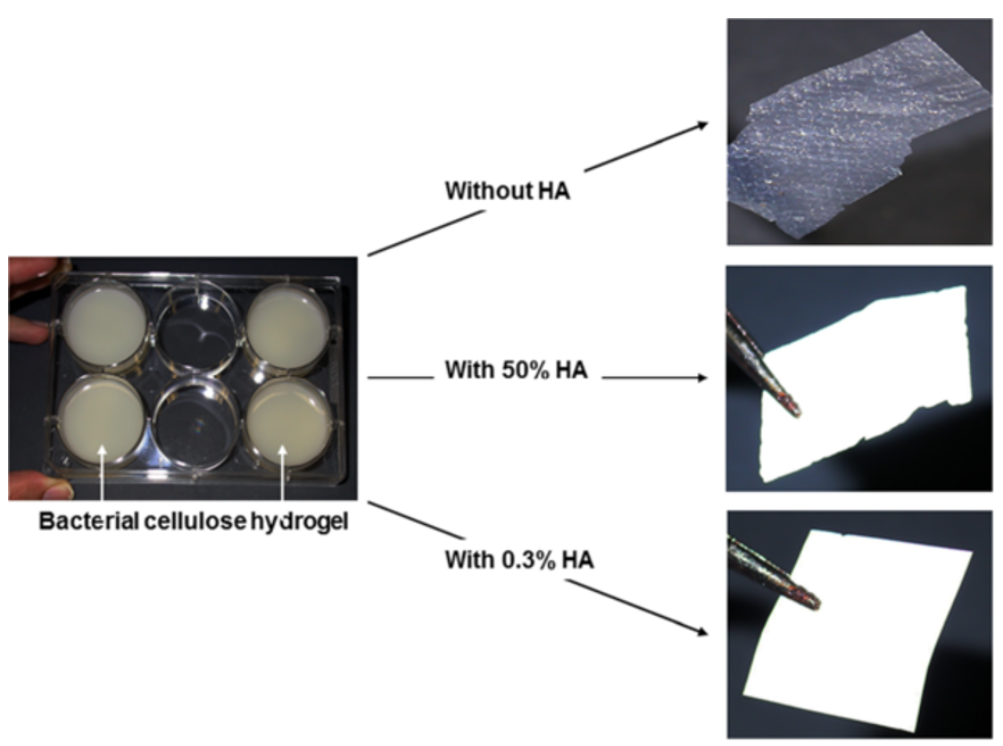

Figure 1 Macroscopic observation of the different BC materials. Note the difference in color and transparency between BC alone and BC supplemented with HA.

Mississauga, ON, Canada) and translated into ALP enzyme activity using a standard curve generated with pnitrophenol (Sigma-Aldrich) ranging in concentration from 0 to $20 \mathrm{mM}$.

Qualitative and quantitative analyses of nodule formation Osteoblasts $\left(5 \times 10^{4}\right)$ were cultured on $\mathrm{BC}$ and $\mathrm{BC} / \mathrm{HA}$ membranes for 3 and 4 weeks. Membranes were washed twice with PBS and then stained with Alizarin Red S (ARS) solution for $2 \mathrm{~min}$ before being washed three times with sodium acetate buffer solution ( $\mathrm{pH}$ 6.3) as we have previously reported (Meng et al., 2011). Mineral nodules were documented by photomicrography at random locations on each membrane. To quantitatively assay nodule mineralization, the ARS stain was dissolved with cetyl-pyridinium chloride (CPC) (Fisher Scientific, Ottawa, ON, Canada) for $1 \mathrm{~h}$ under gentle agitation. One hundred microliters of the CPC from each membrane were transferred to a 96-well plate and diluted with $100 \mu \mathrm{L}$ of water. Absorbance of ARS was determined at $570 \mathrm{~nm}$ by means of the X-Mark Microplate Spectrophotometer (Bio-Rad, $\mathrm{n}=4$ ).

\section{Scanning electron microscopy (SEM) analysis}

Osteoblasts $\left(5 \times 10^{5} / \mathrm{cm}^{2}\right)$ were cultured on $\mathrm{BC}$ and $\mathrm{BC} /$ HA membranes for 2, 4 and 6 days. The membranes were rinsed three times with PBS, fixed in $4 \%$ paraformaldehyde for $15 \mathrm{~min}$, and rinsed again four times in distilled water. Dehydration was performed in a series of ethanol solutions of increasing concentrations (50, 70, 90 , and twice at $100 \%$ ), with a 5-min dehydration treatment in each solution. The dehydrated specimens were kept overnight in a vacuum oven at $25^{\circ} \mathrm{C}$, after which time they were sputter-coated with gold and examined with a JEOL 6360 LV SEM (Soquelec) operating at a 30 $\mathrm{kV}$ accelerating voltage. The experiment was repeated four times and representative photographs were taken $(n=4)$.

\section{Energy dispersive X-ray spectroscope (EDX) analysis}

Osteoblasts $\left(5 \times 10^{5} / \mathrm{cm}^{2}\right)$ were cultured on $\mathrm{BC}$ and $\mathrm{BC} /$ HA membranes for 2, 4 and 6 days. The specimens were then subjected to EDX analyses. The specimens were fixed with ethylene glycol for $30 \mathrm{~min}$ and dried at $50^{\circ} \mathrm{C}$. Following sputter coating with $\mathrm{Au}-\mathrm{Pd}$, the specimens were analyzed by means of EDX using a JEOL 840-A SEM (JEOL, Tokyo, Japan).

Table 1 XPS surface element analyses

\begin{tabular}{lcccccc}
\hline Sample & \multicolumn{7}{c}{ Elements (\%) } \\
\cline { 2 - 7 } & Carbon (C) & Oxygen (O) & Calcium (Ca) & Phosphate (P) & Chloride (Cl) & Sodium (Na) \\
\hline BC & 57 & 42.6 & 0 & 0 & 0.2 & 0 \\
BC-50\%HA & 18 & 49.5 & 9.9 & 9.7 & 2.1 & 10.5 \\
BC-0.3\%HA & 53.4 & 45.9 & 0.4 & 0.2 & 0 & 0 \\
\hline
\end{tabular}

BC: Bacterial cellulose, HA: Hydroxyapatite, XPS: X-ray photoelectron spectroscopy. 


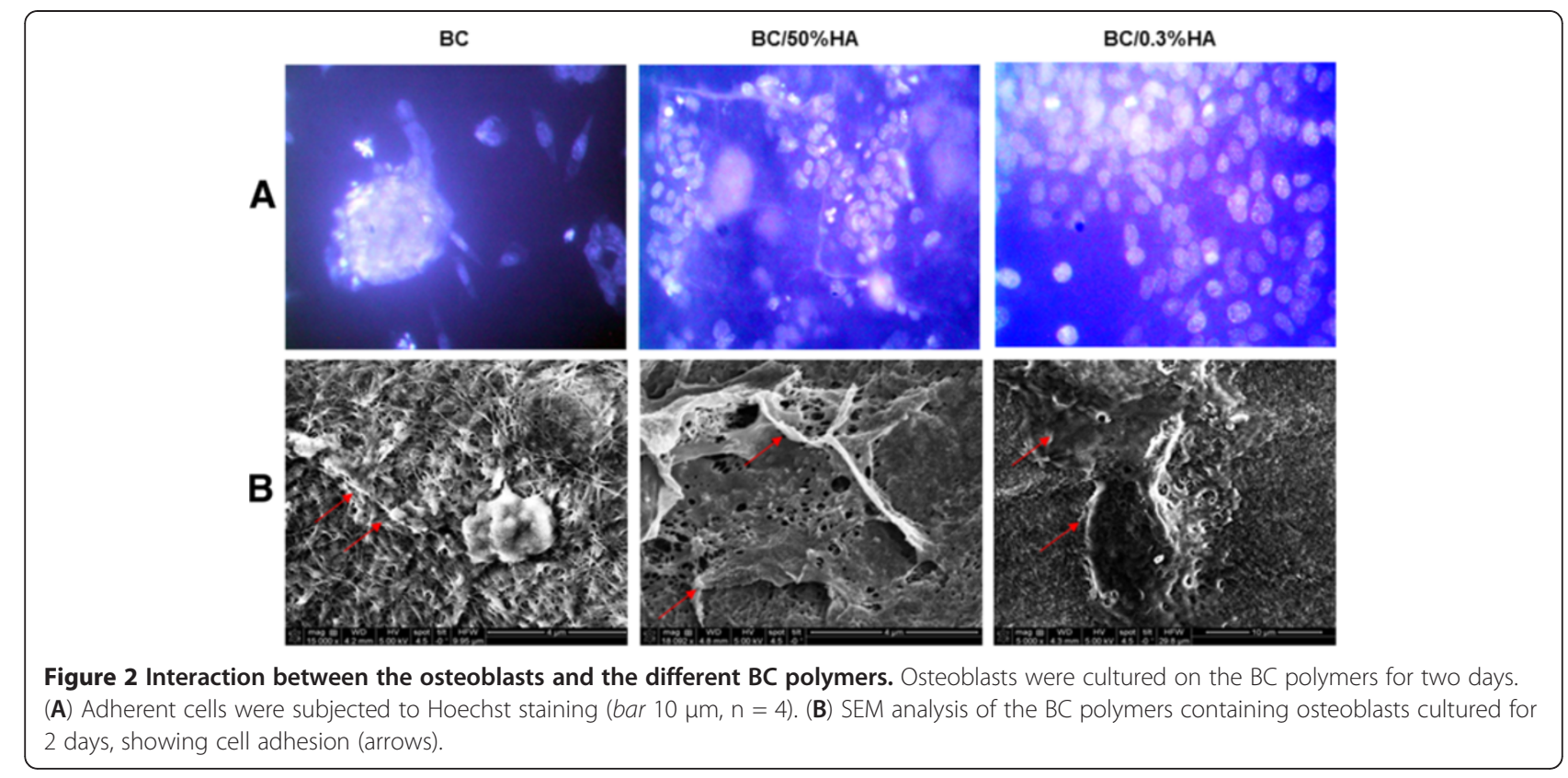

\section{Statistical analysis}

Experimental values are presented as means \pm SD. The statistical significance of differences between the values was evaluated using a one-way ANOVA. Posteriori comparisons were done using Tukey's method. Normality and variance assumptions were verified using the Shapiro-Wilk test and the Brown and Forsythe test, respectively. All of the assumptions were fulfilled. Data were analyzed using the SAS version 8.2 statistical package (SAS Institute Inc., Cary, NC, USA). Results were considered significant at $<0.05$.

\section{Results}

Production of HA enriched bacterial cellulose membrane As shown in Figure 1, BC hydrogel appears as a 3dimensional thick membrane. The membrane was then

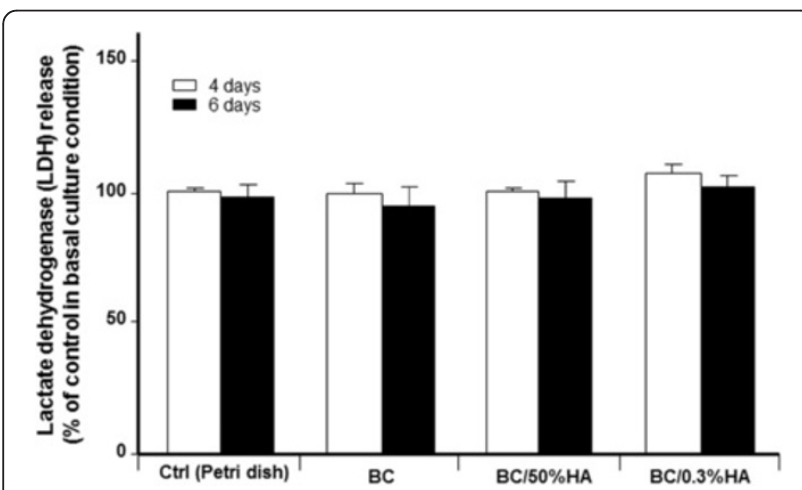

Figure $3 \mathrm{BC}$ polymer has no cytotoxic effect of osteoblasts.

Following osteoblast culture onto each BC polymer for 4 and 6 days, cultured supernatants were used to assess the LDH activity. Note the same levels of $L D H$ with all tested conditions. Data are means + SD, $n=5$. enriched with $\mathrm{HA}$ through alternating incubation cycles in $\mathrm{CaCl}_{2}$ followed by $\mathrm{Na}_{2} \mathrm{HPO}_{4}$ solutions at $25^{\circ} \mathrm{C}$. After drying at $50^{\circ} \mathrm{C}$, we observed a thin, opaque white $\mathrm{BC}$ membrane (Figure 1). The second process incorporating HA into $\mathrm{BC}$ pulp also gave a thin, opaque white $\mathrm{BC}$ membrane (Figure 1). In both HA enriched BC membranes there was $50 \%$ and $0.3 \% \mathrm{HA}$, respectively. To confirm the presence of $\mathrm{HA}$ in the $\mathrm{BC}$ membrane, we performed XPS analyses of the surface elemental composition (\%) of the $\mathrm{BC}$ specimens. All measurements were done at the air-interface. As shown in Table 1, BC membrane alone has 57\% carbon, $42 \%$ oxygen with no calcium and phosphate. In the

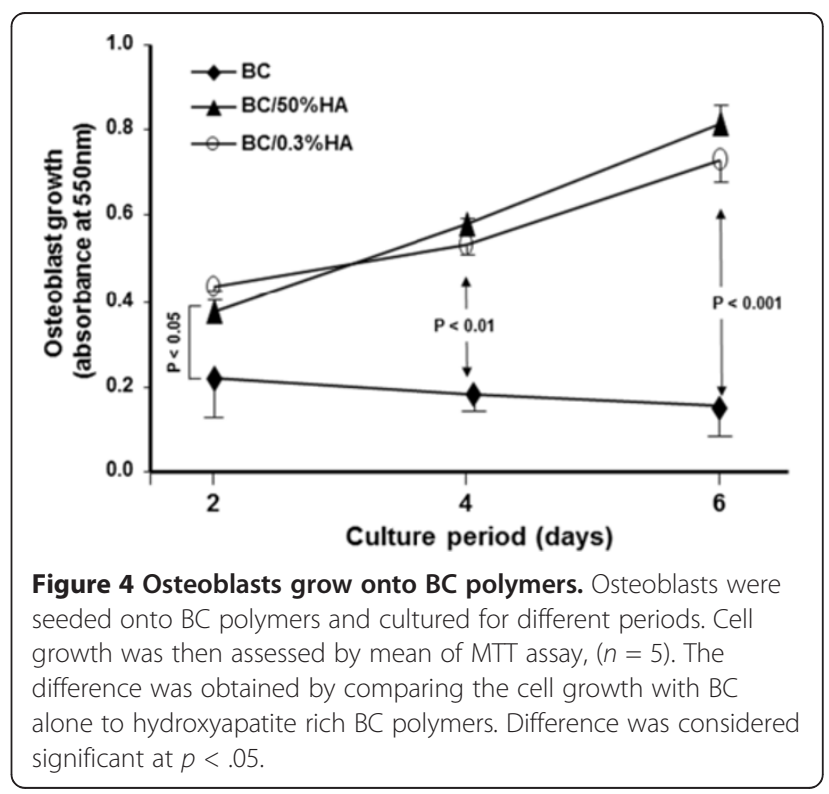




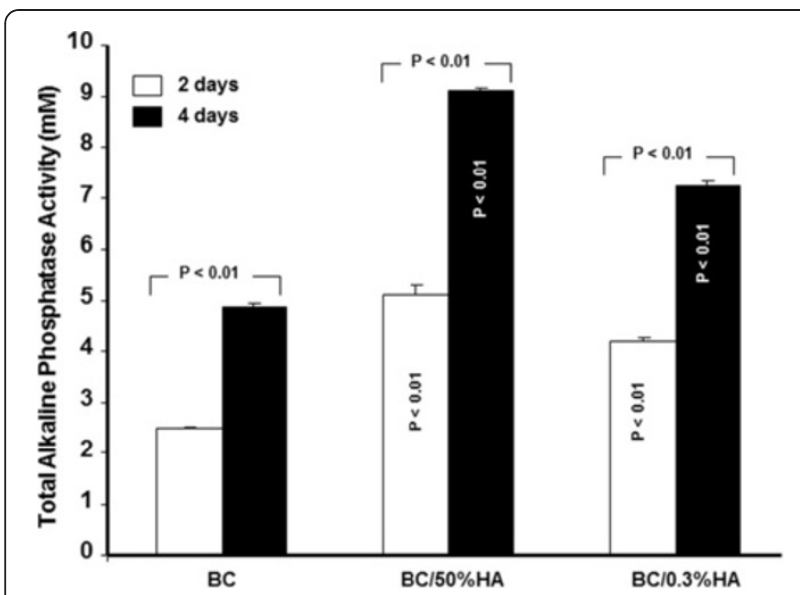

Figure $5 \mathrm{BC}$ polymer with and without hydroxyapatite promotes ALP activity. Following culture onto BC polymers ALP activity was measured by alkaline phosphatase substrate p-NPP. Different levels of ALP activity were observed in the range of 5 to 9 $\mathrm{mM}$ with the hydroxyapatite rich $\mathrm{BC}$ polymers; compared with the $B C$ polymer without hydroxyapatite. Data were presented as the mean + S.D. $(n=4)$.
BC membrane enriched with $50 \%$ of HA, there was $18 \%$ carbon, $49 \%$ oxygen, $10 \%$ calcium and $10 \%$ phosphate on the membrane surface. The level of calcium and phosphate was lower in the cellulose pulp-prepared $\mathrm{BC}$ membrane enriched with only $0.3 \% \mathrm{HA} ; 53 \%$ carbon, $46 \%$ oxygen, $0.4 \%$ calcium and $0.2 \%$ phosphate on the membrane surface. Overall, both methods led to the production of $\mathrm{BC}$ membranes with $\mathrm{HA}$ exposed on the surface, which was expected to be useful for osteoblasts growth.

\section{$B C$ with and without HA promoted osteoblast adhesion}

Following osteoblast seeding and culture on BC membranes, cells were stained with Hoechst. As shown in Figure 2A, BC membranes supported cell adhesion and had no adverse effect on cell morphology. However, osteoblast adhesion was greater on the HA enriched BC membranes. This was confirmed by SEM analyses showing superior cell growth and spreading throughout the surface of the HA enriched $\mathrm{BC}$ membranes (Figure 2B). It is interesting to note that $\mathrm{HA}$ as low as $0.3 \%$ improved osteoblast adhesion. These results clearly demonstrate the compatibility of the $\mathrm{BC}$ membranes used in this study with osteoblasts. We have also shown that the addition of HA enhanced osteoblast adhesion and
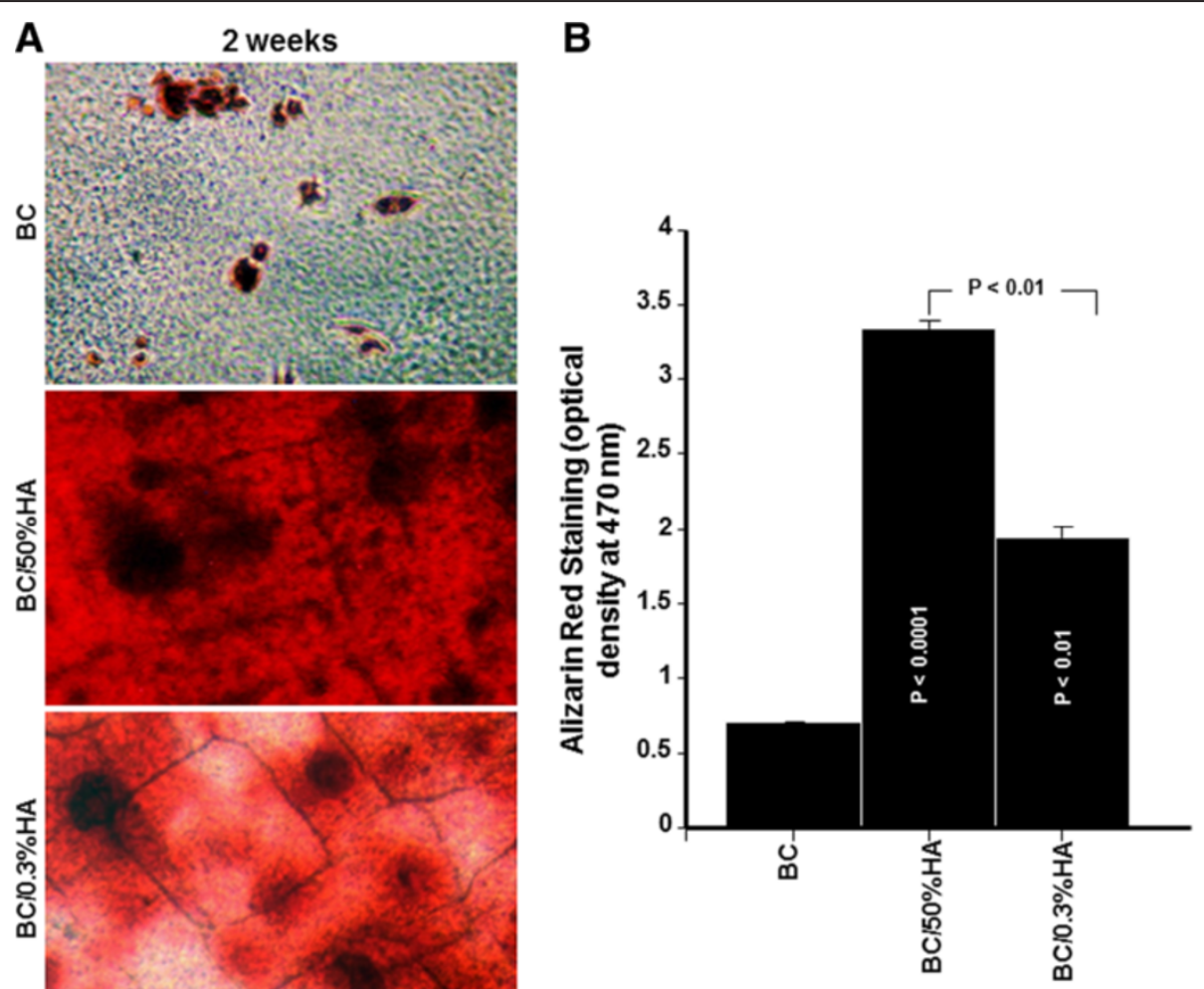

Figure 6 BC polymer promotes Osteoblast mineralization. Osteoblasts were culture onto the BC polymers for 2 weeks. Cells were fixed and stained with $0.5 \%$ alizarin red. Subsequently the alizarin red stain was eluted with cetylpyridinium chloride and measured quantitatively. Panel (A) photographs show the extent of mineralization (bar $=10 \mu \mathrm{m})$. Panel $(\mathbf{B})$ graph represents the mean $+\mathrm{SD}(n=5)$. 


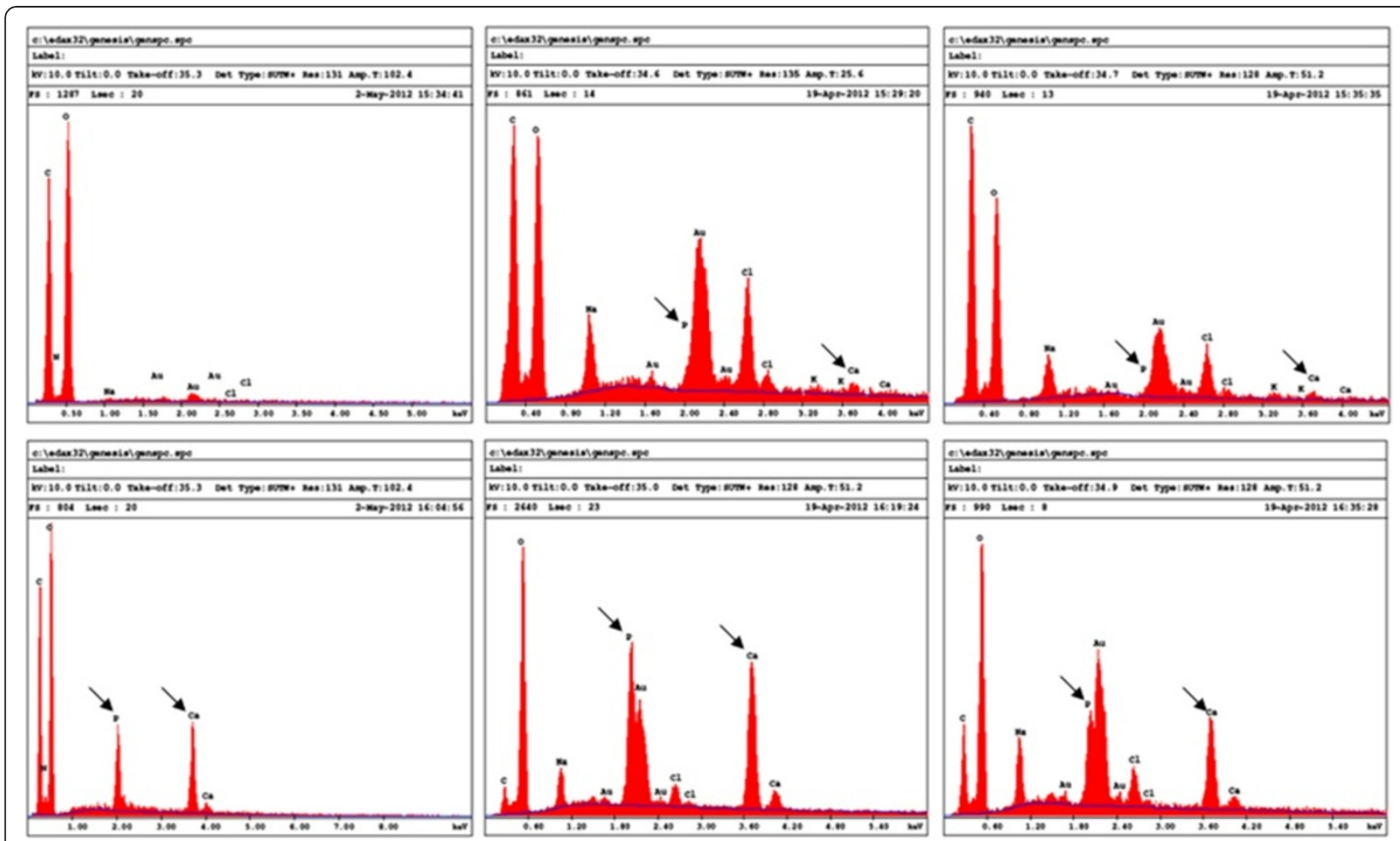

Figure 7 EDX microanalysis of nodules osteoblast seeded and non-seeded BC polymers. BC Polymers were seeded or not with osteoblasts then cultured for 6 days. They were then subjected to EDX analyses for phosphate and calcium element detection along with other elements. Element values were reported in Table 2. Representative grafts $(n=4)$.

spreading. To further confirm the non-toxicity of $\mathrm{BC}$, as shown in Figure 3, the release of LDH activity was comparable between $\mathrm{BC}$ membranes and tissue culture plates.

\section{BC with and without HA promote osteoblast proliferation} Because osteoblasts adhered to the $\mathrm{BC}$ membranes, we assessed their proliferation potential using the MTT assay. As shown in Figure 4, BC was able to support osteoblast adhesion and growth. However, both HA enriched $\mathrm{BC}$ membranes demonstrated significantly higher osteoblast growth when compared to the $\mathrm{BC}$ membrane without HA. Osteoblasts cultured on the $\mathrm{BC} /$ HA membranes showed exponential growth up to 6 days. Interestingly, even at a level as low as $0.3 \%$, HA promoted osteoblast proliferation which was compatible to osteoblast growth on $\mathrm{BC}$ membranes containing $50 \%$ $\mathrm{HA}$. The overall results suggest that $\mathrm{HA}$ enriched $\mathrm{BC}$ is superior to $\mathrm{BC}$ alone for osteoblast proliferation. It should be noted that the lower osteoblast growth of $\mathrm{BC}$ membrane alone was not due to cellular toxicity of BC.

\section{Osteoblast cultured onto different BC materials secreted ALP}

Both $\mathrm{BC}$ and $\mathrm{BC} / \mathrm{HA}$ membranes promote ALP production from osteoblasts (Figure 5), which increased with time of culture. For the BC membrane alone, ALP concentration went from $2.5 \mathrm{mM}$ on day two to almost $5 \mathrm{mM}$ on day four. The presence of HA in the $\mathrm{BC}$ membrane significantly promoted the ALP activity as compared to $\mathrm{BC}$ alone. Indeed, with the $\mathrm{BC} / \mathrm{HA}(0.3 \%)$ membrane, ALP activity was more than $4 \mathrm{mM}$ at day two and $7 \mathrm{mM}$ at day four ( $\mathrm{p}$ both $<0.01$ ). Even greater ALP activity was seen with the BC/HA (50\%) membrane; $5 \mathrm{mM}$ at day two and $9 \mathrm{mM}$ at day four. These data show that osteoblasts cultured on BC have ALP activity and furthermore, this activity increases when the $\mathrm{BC}$ polymer is supplemented with HA.

\section{BC promotes osteoblast mineralization}

Because osteoblasts were able to adhere to $\mathrm{BC}$ membranes and proliferate, we investigated the mineralization process using the ARS assay. As shown in Figure 6A, multiple nodules were observed after two weeks of culture. However, the number and size of nodules were greater for the $\mathrm{HA}$ enriched $\mathrm{BC}$ membranes than for the HA free $\mathrm{BC}$ membranes. This was confirmed by quantitative analyses using a CPC assay. ARS levels were significantly greater with the $\mathrm{BC} / \mathrm{HA}$ membranes than with the $\mathrm{BC}$ membrane (Figure 6B). These data suggest the osteogenic potential of $\mathrm{BC}$ polymer which is synergistic with HA. Confirmation of 
Table 2 Quantification of the surface chemical elements of the different BC polymers by EDX

\begin{tabular}{|c|c|c|c|c|c|c|}
\hline \multirow{2}{*}{\multicolumn{4}{|c|}{\begin{tabular}{l} 
EDAX ZAF Quantification (Standardless) \\
Element normalized \\
SKC Table: Default \\
\multicolumn{1}{c}{ Without osteoblasts }
\end{tabular}}} & \multirow{2}{*}{\multicolumn{3}{|c|}{ With osteoblasts }} \\
\hline & & & & & & \\
\hline & Element & Wt \% & At $\%$ & Element & Wt \% & $\overline{\text { At } \%}$ \\
\hline \multirow[t]{10}{*}{$\overline{B C}$} & CK & 44.28 & 53.71 & CK & 30.31 & 42.98 \\
\hline & NK & 2.87 & 2.99 & NK & 6.38 & 7.76 \\
\hline & OK & 46.73 & 42.55 & OK & 33.36 & 35.52 \\
\hline & PK & 0.00 & 0.00 & PK & 8.07 & 4.44 \\
\hline & $\mathrm{Na} \mathrm{K}$ & 0.35 & 0.22 & $\mathrm{NaK}$ & 0.00 & 0.00 \\
\hline & Au K & 5.48 & 0.04 & Au K & 0.00 & 0.00 \\
\hline & $\mathrm{Cl} \mathrm{K}$ & 0.29 & 0.003 & $\mathrm{Cl} \mathrm{K}$ & 0.00 & 0.00 \\
\hline & $\mathrm{Ca} \mathrm{K}$ & 0.00 & 0.00 & $\mathrm{Ca} \mathrm{K}$ & 21.88 & 9.30 \\
\hline & Total & $100 \%$ & $100 \%$ & & & \\
\hline & Element & Wt \% & At $\%$ & Element & Wt \% & At $\%$ \\
\hline \multirow[t]{10}{*}{ BC-50\%HA } & CK & 38.58 & 64.07 & $C K$ & 4.67 & 11.76 \\
\hline & $\mathrm{OK}$ & 19.15 & 23.89 & OK & 25.01 & 46.87 \\
\hline & $\mathrm{NaK}$ & 3.00 & 2.60 & $\mathrm{NaK}$ & 2.18 & 2.84 \\
\hline & PK & 1.13 & 0.73 & PK & 11.65 & 11.28 \\
\hline & Au K & 27.29 & 2.76 & Au K & 25.45 & 3.87 \\
\hline & $\mathrm{Cl} \mathrm{K}$ & 8.55 & 4.81 & $\mathrm{Cl} \mathrm{K}$ & 2.55 & 2.16 \\
\hline & KK & 0.73 & 0.37 & KK & 0.00 & 0.00 \\
\hline & $\mathrm{Ca} \mathrm{K}$ & 1.54 & 0.78 & $\mathrm{Ca} \mathrm{K}$ & 28.49 & 21.31 \\
\hline & Total & $100 \%$ & $100 \%$ & & & \\
\hline & Element & Wt \% & At $\%$ & Element & Wt \% & At $\%$ \\
\hline \multirow[t]{9}{*}{$\mathrm{BC}-0.3 \% \mathrm{HA}$} & CK & 46.09 & 68.54 & CK & 13.87 & 32.64 \\
\hline & OK & 20.47 & 22.85 & OK & 21.50 & 37.99 \\
\hline & $\mathrm{NaK}$ & 2.60 & 2.02 & $\mathrm{NaK}$ & 3.36 & 4.13 \\
\hline & PK & 0.67 & 0.39 & PK & 6.09 & 5.56 \\
\hline & Au K & 21.44 & 1.95 & Au K & 34.92 & 5.01 \\
\hline & $\mathrm{Cl} \mathrm{K}$ & 6.24 & 3.14 & $\mathrm{Cl} \mathrm{K}$ & 4.02 & 3.20 \\
\hline & K K & 1.03 & 0.47 & K K & 0.00 & 0.00 \\
\hline & $\mathrm{Ca} \mathrm{K}$ & 1.45 & 0.65 & $\mathrm{CaK}$ & 16.25 & 11.46 \\
\hline & Total & $100 \%$ & $100 \%$ & Total & $100 \%$ & $100 \%$ \\
\hline
\end{tabular}

BC: bacterial cellulose, EDX: Energy dispersive X-ray.

mineralization was performed by EDX analysis. As shown in Figure 7, all of the EDX analyses revealed rich calcium and phosphate deposits on the surface of the osteoblast-seeded $\mathrm{BC}$ membranes as compared to the cell free membranes. The peaks referring to phosphate and calcium were greater in the osteoblast seeded $\mathrm{BC}$ polymers as compared to non-seeded membranes. This was supported by quantitative analyses shown in Table 2 . Indeed, in $\mathrm{HA}$ free $\mathrm{BC}$ polymer the phosphate and calcium elements were undetectable. However, when osteoblasts were cultured for 6 days, the phosphate and calcium levels were 8 and 21 wt\% respectively, demonstrating phosphate and calcium production by osteoblasts and deposition onto the $\mathrm{BC}$ polymer surface. The levels of both phosphate and calcium were further increased with HA enriched BC membranes seeded with osteoblasts (Table 2). Together, these data demonstrate the osteogenic nature of the $\mathrm{BC}$ polymer, and the possibility to improve this osteogenic property by adding a natural component to the $\mathrm{BC}$ membrane such as HA.

\section{Discussion}

In the present study we demonstrate the feasibility of producing bacterial cellulose and incorporating into this polymer, a native bone material, HA. HA incorporation was done through two processes using either BC hydrogel or $\mathrm{BC}$ pulp before polymer casting. This confirms previously reported data related to HA incorporation of bacterial cellulose (Hutchens et al., 2006; Wan et al., 2009). The presence of HA in the BC was confirmed by XPS analyses showing that even with low initial $(0.3 \%)$ HA concentration, we were able to produce a calcium and phosphate rich $\mathrm{BC}$ membrane. The presence of $\mathrm{BC}$ surface calcium and phosphate is expected to promote cell adhesion and growth (Saska et al. 2011; Akkouch et al., 2011). This hypothesis is supported by osteoblast culture on different $\mathrm{BC}$ membranes showing that osteoblasts adhere to the surface of the polymer. However, the adherent cells were not able to sustain growth over time. In fact, proliferation decreases with time of culture. This is contradictory to what has been reported previously (Ferreira et al., 2010; Andersson et al., 2010; Saska et al., 2012). This difference could be due to the experimental condition used including seeding concentration. Indeed, Ferreira et al. (2009) showed that fibroblasts seeded at high concentration achieved better adhesion rates than low seeding concentration. Alternatively, a recent study reported low cell growth and low cell activity when cells were cultured on $\mathrm{BC}$ alone in comparison with a growth factor, BMP2 supplemented BC (Sun et al., 2012). It is important to note that the low adhesion and proliferation levels of osteoblasts on $\mathrm{BC}$ were not simply due to a cytotoxic effect. Indeed, the LDH level was not significantly different using $B C$ as compared to $\mathrm{BC}$ enriched with $\mathrm{HA}$. The potential reduction of cell number over culture time could be due an apoptotic process of differentiated cells (Shi et al., 2012), or simply due to the emergence of osteoblasts into a nondividing G0 phase (Boissinot et al., 2012). Further work is required to address these issues.

The low adhesion and proliferation levels of osteoblasts were significantly $(\mathrm{p}<0.05)$ improved by the addition of HA (Blomquist et al., 1979). Indeed, as demonstrated in this study, adhesion and growth of osteoblasts onto HA supplemented $\mathrm{BC}$ were greater as 
compared to $\mathrm{BC}$ alone. For example, proliferation was 2, 3 and 6 times higher for the HA enriched $\mathrm{BC}$ than for HA free BC. The availability of HA at the surface improved both cell attachment and proliferation (Blomquist et al., 1979; Lock et al., 2012). Interestingly, even with low level $(0.3 \%)$ HA in the BC membrane, osteoblasts adhere well and proliferate. The osteogenic activity of BC polymer was supported by increased ALP activity over culture time. However, ALP activity was greater in $\mathrm{HA}$ enriched $\mathrm{BC}$ than in $\mathrm{BC}$ polymer alone. This confirms a previously reported observation when BC was supplemented with another growth factor, BMP2 (Sun et al., 2012).

The bacterial cellulose environment promoting osteoblast adhesion and growth is favored by the presence of calcium and phosphate elements on the surface of the $\mathrm{BC} /$ HA (Polini et al., 2011; Strobel et al., 2012). In this environment, osteoblasts were able to form bone nodules. This is due to an active mineralization process through the secretion and deposition of mineralizing elements including calcium and phosphate on the surface of the $\mathrm{BC}$ membrane (Figure 7, Table 2). Indeed, following osteoblast culture on $\mathrm{BC}$ polymers, the levels of calcium and phosphate increased. In the $\mathrm{HA}$ free $\mathrm{BC}$ polymer, the calcium levels increased from zero with non-cell seeded $\mathrm{BC}$ to $21.8 \%$ in the osteoblast seeded BC polymer. The same observation was made with phosphate. This supports the hypothesis that osteoblasts maybe differentiating more than proliferating when cultured on BC polymer (Polini et al., 2011; Strobel et al., 2012; Ogata et al., 2012). Such differentiation would support the bone nodule formation we have shown. In conclusion, BC cellulose alone supports osteoblast adhesion but preserves the osteoblast in a non-dividing (G0) state. In this situation, osteoblasts differentiate leading to tissue mineralization through nodule formation as demonstrated by the high percentage of calcium and phosphate on the $\mathrm{BC}$ polymer surface. Interestingly, when $\mathrm{BC}$ is supplemented with HA, osteoblasts adhere, proliferate and mineralize better as compared to the $\mathrm{BC}$ polymer alone. Together, these data suggest that $\mathrm{BC}$ could be an appropriate support for bone tissue engineering. With the incorporation of active molecules such as HA and BMP2 the osteogenic potential of bacterial cellulose polymers may be optimized for multiple tissue engineering tools.

\section{Competing interest}

The authors declare that they have no competing interests.

\section{Acknowledgements}

Authors would like to acknowledge The Canada Excellence Research Chair (CERC-Chaire d'excellence en recherche du Canada sur l'innovation en photonique dans le domaine de l'information et des communications), and the NSERCs Discovery Program for the financial for support. The authors would also like to acknowledge the technical support of Dr. Semlali Abdelhabib, Dr. Adil Akkouch, Mss Ozra Pouraghajani, Marcia G.B. Silva and Marco Aurélio Napolitano.

\section{Author details}

'Groupe de Recherche en Écologie Buccale, Faculté de Médecine Dentaire, Université Laval, 2420, rue de la Terrasse, Québec, QC G1V OA6 Québec, Canada. ${ }^{2}$ Département de chirurgie, Faculté de médecine, Université Laval, Centre de recherche de l'Hôpital Saint-François d'Assise, CHUQ, Québec, QC, Canada. ${ }^{3}$ Département de physique, génie physique et d'optique, Faculté de Sciences et génie, Université Laval, Québec, QC, Canada. ${ }^{4}$ DMC

Equipamentos, Sao Carlos, SP, Brazil. ${ }^{5}$ Department of medicine, University of Illinois, Chicago, USA.

Received: 8 November 2012 Accepted: 9 November 2012

Published: 22 November 2012

\section{References}

Akkouch A, Zhang Z, Rouabhia M (2011) A novel collagen/hydroxyapatite/poly

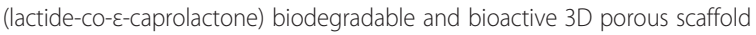
for bone regeneration. J Biomed Mater Res A 96:693-704

Andersson J, Stenhamre H, Bäckdahl H, Gatenholm P (2010) Behavior of human chondrocytes in engineered porous bacterial cellulose scaffolds. J Biomed Mater Res A 94:1124-1132

Andrade FK, Costa R, Domingues L, Soares R, Gama M (2010) Improving bacterial cellulose for blood vessel replacement: functionalization with a chimeric protein containing a cellulose-binding module and an adhesion peptide. Acta Biomater 6:4034-4041

Bäckdahl H, Helenius G, Bodin A, Nannmark U, Johansson BR, Risberg B, Gatenholm P (2006) Mechanical properties of bacterial cellulose and interactions with smooth muscle cells. Biomaterials 27:2141-2149

Bitar M, Brown RA, Salih V, Kidane AG, Knowles JC, Nazhat SN (2008) Effect of cell density on osteoblastic differentiation and matrix degradation of biomimetic dense collagen scaffolds. Biomacromolecules 9:129-135

Blomquist E, Arro E, Brunk U, Westermark B (1979) Growth stimulation of aged cells in culture. Acta Pathol Microbiol Scand A 87A:393-399

Bodin A, Gustafsson L, Gatenholm P (2006) Surface-engineered bacterial cellulose as template for crystallization of calcium phosphate. J Biom 17:435-447

Boissinot M, Inman M, Hempshall A, James SR, Gill JH, Selby P, Bowen DT, Grigg R, Cockerill PN (2012) Induction of differentiation and apoptosis in leukaemic cell lines by the novel benzamide family histone deacetylase 2 and 3 inhibitor MI-192. Leuk Res 36:1304-1310

Bostrom MP, Saleh KJ, Einhorn TA (1999) Osteoinductive growth factors in preclinical fracture and long bone defects models. Orthop Clin North Am 30:647-658

Buxton PG, Cobourne MT (2007) Regenerative approaches in the craniofacial region: manipulating cellular progenitors for oro-facial repair. Oral Dis 13:452-460

Denizot F, Lang R (1986) Rapid colorimetric assay for cell growth and survival. Modifications to the tetrazolium dye procedure giving improved sensitivity and reliability. J Immunol Methods 89:271-277

Fang B, Wan YZ, Tang T, Gao C, Dai KR (2009) Proliferation and osteoblastic differentiation of human bone marrow stromal cells on hydroxyapatite/ bacterial cellulose nanocomposite scaffolds. Tissue Eng Part A 15:1091-1098

Ferreira LM, Sobral CS, Blanes L, Ipolito MZ, Horibe EK (2010) Proliferation of fibroblasts cultured on a hemi-cellulose dressing. J Plast Reconstr Aesthet Surg 63:865-869

Franceschi RT (2005) Biological approaches to bone regeneration by gene therapy. J Dent Res 84:1093-1103

Garg T, Singh O, Arora S, Murthy R (2012) Scaffold: a novel carrier for cell and drug delivery. Crit Rev Ther Drug Carrier Syst 29:1-63

Gleitz J, Tosch C, Peters T (1996) Continuous enzyme-linked fluorometric detection of $\mathrm{L}-(+)$-lactate released from rat brain vesicles under anoxic conditions. J Neurosci Methods 67:97-102

Gong Y, Zhou Q, Gao C, Shen J (2007) In vitro and in vivo degradability and cytocompatibility of poly(l-lactic acid) scaffold fabricated by a gelatin particle leaching method. Acta Biomater 3:531-540

Grande CJ, Torres FG, Gomez CM, Bano MC (2009) Nanocomposites of bacterial cellulose/hydroxyapatite for biomedical applications. Acta Biomat 25:1605-1615

Harris LD, Kim BS, Mooney DJ (1998) Open pore biodegradable matrices formed with gas foaming. J Biomed Mater Res 42:396-402

Hasegawa S, Neo M, Tamura J, Fujibayashi S, Takemoto M, Shikinami Y, Okazaki K, Nakamura T (2007) In vivo evaluation of a porous hydroxyapatite/poly-DL- 
lactide composite for bone tissue engineering. J Biomed Mater Res A 81:930-938

Helenius G, Bäckdahl H, Bodin A, Nannmark U, Gatenholm P, Risberg B (2006) In vivo biocompatibility of bacterial cellulose. J Biomed Mater Res A 76:431-438

Holland TA, Mikos AG (2006) Biodegradable polymeric scaffolds. Improvements in bone tissue engineering through controlled drug delivery. Adv Biochem Eng Biotechnol 102:161-185

Hong L, Wang Y, Jia S, Huang Y, Gao C, Wan Y (2006) Hydroxyapatite/bacterial cellulose composites synthesized via a biomimetic route. Mater Letters 60:1710-1713

Huang X, Yang D, Yan W, Shi Z, Feng J, Gao Y, Weng W, Yan S (2007) Osteochondral repair using the combination of fibroblast growth factor and amorphous calcium phosphate/poly(L-lactic acid) hybrid materials. Biomaterials 28:3091-3100

Hutchens SA, Benson RS, Evans BR, O'Neill HM, Rawn CJ (2006) Biomimetic synthesis of calcium-deficient hydroxyapatite in a natural hydrogel. Biomaterials 27:4661-4670

Lock J, Nguyen TY, Liu H (2012) Nanophase hydroxyapatite and poly(lactide-coglycolide) composites promote human mesenchymal stem cell adhesion and osteogenic differentiation in vitro. J Mater Sci Mater Med. doi:10.1007/ s10856-012-4709-0

Melo JB, Agostinho P, Oliveira CR (2007) Prion protein aggregation and neurotoxicity in cortical neurons. Ann N Y Acad Sci 1096:220-229

Meng S, Zhang Z, Rouabhia M (2011) Accelerated osteoblast mineralization on a conductive substrate by multiple electrical stimulation. J Bone Miner Metab 29:535-544

O'Brien FJ, Harley BA, Waller MA, Yannas IV, Gibson LJ, Prendergast PJ (2007) The effect of pore size on permeability and cell attachment in collagen scaffolds for tissue engineering. Technol Health Care 15:3-17

Ogata H, Hayashi M, Tsuda H, Suzuki N, Maeno M, Sugawara A, Ogiso B (2012) Effects of a calcium phosphate cement on mineralized nodule formation compared with endodontic cements. Dent Mater J 31:92-97

Oliver RC, Brown L, Löe H (1998) Periodontal diseases in the United States population. J Periodontol 69:269-278

Polini A, Pisignano D, Parodi M, Quarto R, Scaglione S (2011) Osteoinduction of human mesenchymal stem cells by bioactive composite scaffolds without supplemental osteogenic growth factors. PLoS One 6:e26211

Saska S, Barud HS, Gaspar AM, Marchetto R, Ribeiro SJ, Messaddeq Y (2011) Bacterial cellulose-hydroxyapatite nanocomposites for bone regeneration. Int J Biomater 2011:175362

Saska S, Scarel-Caminaga RM, Teixeira LN, Franchi LP, Dos Santos RA, Gaspar AM, de Oliveira PT, Rosa AL, Takahashi CS, Messaddeq Y, Ribeiro SJ, Marchetto R (2012) Characterization and in vitro evaluation of bacterial cellulose membranes functionalized with osteogenic growth peptide for bone tissue engineering. J Mater Sci Mater Med. doi:10.1007/s10856-012-4676-5

Shi Q, Li Y, Sun J, Zhang H, Chen L, Chen B, Yang H, Wang Z (2012) The osteogenesis of bacterial cellulose scaffold loaded with bone morphogenetic protein-2. Biomaterials 33:6644-6649

Strobel L, Rath S, Maier A, Beier J, Arkudas A, Greil P, Horch R, Kneser U (2012) Induction of bone formation in biphasic calcium phosphate scaffolds by bone morphogenetic protein-2 and primary osteoblasts. J Tissue Eng Regen Med. doi:10.1002/term.1511

Sun L, Zhang L, Hemraz UD, Fenniri H, Webster TJ (2012) Bioactive Rosette nanotube-hydroxyapatite nanocomposites improve osteoblast functions. Tissue Eng Part A. doi:10.1089/ten.tea.2011.0456

Varma HK, Babu SS (2005) Synthesis of calcium phosphate bioceramics by citrate gel pyrolysis method. Ceram Int 31:109-114

Wahl DA, Sachlos E, Liu C, Czernuszka JT (2007) Controlling the processing of collagen-hydroxyapatite scaffolds for bone tissue engineering. J Mater Sci Mater Med 18:201-209

Wan YZ, Gao C, Luo HL, He F, Liang H, Li XL, Wang YL (2009) Early growth of nano-sized calcium phosphate on phosphorylated bacterial cellulose nanofibers. J Nanosci Nanotechnol 9:6494-6500

Wang H, Li Y, Zuo Y, Li J, Ma S, Cheng L (2007) Biocompatibility and osteogenesis of biomimetic nano-hydroxyapatite/polyamide composite scaffolds for bone tissue engineering. Biomaterials 28:3338-3348

doi:10.1186/2191-0855-2-61

Cite this article as: Tazi et al:: Hydroxyapatite bioactivated bacterial cellulose promotes osteoblast growth and the formation of bone nodules. AMB Express 2012 2:61.

\section{Submit your manuscript to a SpringerOpen ${ }^{\circ}$ journal and benefit from:}

- Convenient online submission

- Rigorous peer review

- Immediate publication on acceptance

- Open access: articles freely available online

- High visibility within the field

- Retaining the copyright to your article

Submit your next manuscript at $>$ springeropen.com 